\title{
NIKOLAI ALEKSANDROVICH VAVILOV
}

On September 17, 2012 Nikolai Aleksandrovich Vavilov turned sixty years old. The personality of Nikolai Aleksandrovich is so bright that he conveys it to all around him. It helps him to look for best solutions of the problems he attends to. He was one of the strongest pupils of School No. 30 and an outstanding student of the Faculty of Mathematics and Mechanics in St. Petersburg University. It was fortunate indeed for the Department of Algebra that Vavilov chose algebra as his speciality.

An immediate teacher of Vavilov was Zenon Ivanovich Borewicz, but for good reason Nikolai Aleksandrovich considers D. K. Faddeev his teacher too. Dmitrii Konstantinovich always kept a close watch on the progress of N. A. in science and admired his capacity for work. When after his academic trip to Poland, N. A. gave a report on his results, Faddeev said that he did not expect that a single person could do so much in so short a time.

The main field of research of Vavilov is the structure theory of Chevalley groups over rings. N. A. has created a fruitful scientific direction in this area. There are hundreds (maybe, thousands) papers devoted to the topic that he has developed, and the leading role is played here by Vavilov himself and the school that he has generated. Not to repeat ourselves, we refer the reader to the paper in the first issue of Vestnik SPbGU for this year.

All the life of Nikolai Aleksandrovich has been closely connected with St. Petersburg State University; he is one of the most active professors of the Faculty of Mathematics and Mechanics and the Faculty of Economics. Vavilov has expended much time and energy in teaching. He delivered many lectures and special courses, conducted seminars, and wrote books. Moreover, N. A. teaches computer algebra to the students; he was among the first to apply computer calculations in group theory. His immense erudition enables him to give lectures on the history of mathematics as well.

The journeys of Vavilov all over the world should be pointed out separately. He visited all the continents (except for Antarctida) with research and education aims. In recent years he has frequented Asian scientific centers and universities. This is maintained by the remarkable talent of Nikolai Aleksandrovich for foreign languages, which he has learned at a deep linguistic level.

Over many years N. A. Vavilov has been a coeditor of our "Zapiski." The number of his papers (with coauthors and without) is enormous. His scientific work can be depicted by words of an old epigram dedicated to I. Erenburg:

$$
\begin{aligned}
& \text { "Fundamental as she-elephants } \\
& \text { and as doe rabbits is fertile." }
\end{aligned}
$$

We are sure that for many years he will create his mathematical chefs-d'oeuvre and delight us many more times with his ebullient temperament.

Friends, colleagues, and pupils of

Nikolai Aleksandrovich 